\title{
Highly Efficient Oxygen Reduction Catalysts by Rational Synthesis of Nanoconfined Maghemite in a Nitrogen-Doped Graphene Framework
}

\author{
Kaipei Qiu, ${ }^{* \dagger}{ }^{\dagger}$ Guoliang Chai, ${ }^{\dagger}$ Chaoran Jiang, ${ }^{\ddagger}$ Min Ling, ${ }^{\dagger}$ Junwang Tang, ${ }^{\ddagger}$ and Zhengxiao Guo ${ }^{*}, \dagger$ \\ ${ }^{\dagger}$ Department of Chemistry, University College London, 20 Gordon Street, London WC1H 0AJ, U.K. \\ ${ }^{\ddagger}$ Department of Chemical Engineering, University College London, Torrington Place, London WC1E 7JE, U.K.
}

Supporting Information

ABSTRACT: The oxygen reduction reaction (ORR) is critical for electrochemical energy storage and conversion: e.g., in fuel cells and metal-air batteries. A major challenge is to develop cost-effective and durable ORR catalysts, to replace the relatively expensive platinum-loaded carbon ( $\mathrm{PtC}$ ) counterparts, particularly for large-scale applications. Despite progress over the past few decades in developing efficient non-precious-metal (NPM) catalysts, such as $\mathrm{Fe} / \mathrm{N} / \mathrm{C}-$ based materials (the best-known alternatives), most of the reported catalytic activities have yet to match that of $\mathrm{PtC}$. Herein we propose a two-step process for the production of highly efficient NPM catalysts that outperform PtC in alkaline media: (1) a hierarchical porosity of a supporting substrate is generated and optimized in advance, especially to achieve a high total pore volume for rapid mass transfer, and (2) an appropriate amount of NPM precursor is added to the optimized substrate to boost the reduction potential while maintaining the hierarchically porous structure. Such a scheme was successfully applied to a case of

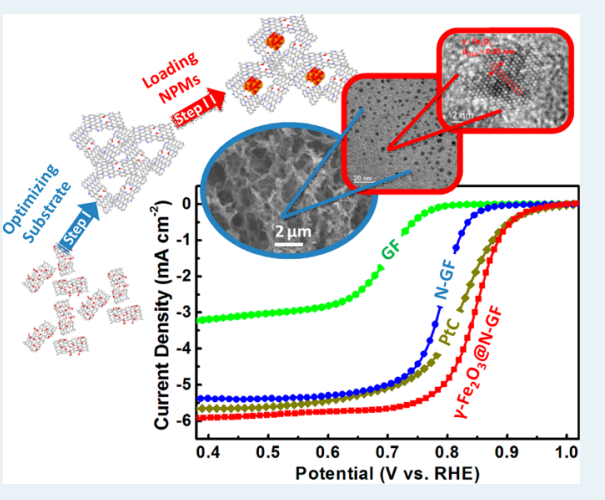
nanoconfined maghemite $\left(\gamma-\mathrm{Fe}_{2} \mathrm{O}_{3}\right)$ in a nitrogen-doped graphene framework. The resulting catalyst system surpasses the performance of the equivalent commercial $\mathrm{PtC}$, in terms of a higher reduction potential, a significantly lower peroxide formation ratio, more than tripled kinetic current density, smaller Tafel slope, better durability, etc. The reported catalyst is also among the best of all the existing Fe-based ORR catalysts, indicating the great potential of $\gamma-\mathrm{Fe}_{2} \mathrm{O}_{3}$ for ORR in practical applications.

KEYWORDS: oxygen reduction reaction, hierarchical graphene framework, nitrogen doping, maghemite, alkaline electrolyte

\section{INTRODUCTION}

Increasing demand for large-scale metal-air batteries and alkaline fuel cells has led to considerable effort in developing cost-effective and durable non-precious-metal (NPM) catalysts, particularly to replace the commercial platinum supported on carbon (PtC) for oxygen reduction reactions (ORR) in alkaline electrolytes. ${ }^{1}$ The kinetics of ORR is faster in an alkaline than in an acidic media, featured by a smaller overpotential and a higher exchange current, primarily due to the reduction of the thermodynamic barrier as the $\mathrm{pH}$ of electrolyte increases. ${ }^{2}$ Such an advantage gives rise to the possibility of applying a wide range of NPM catalysts, even those with a relatively weak oxygen binding energy. ${ }^{3}$ In fact, to achieve comparable ORR activities, a relatively small amount of NPM catalysts is generally required, e.g. in $0.1 \mathrm{M} \mathrm{KOH}$ than in $0.5 \mathrm{M} \mathrm{H}_{2} \mathrm{SO}_{4}$ or $0.1 \mathrm{M} \mathrm{HClO}_{4}{ }^{4}$ implying the development of practical $\mathrm{Pt}$ alternatives is more feasible in an alkaline environment.

The best-known NPM ORR catalysts consist of nitrogen, carbon, and transition metals, such as $\mathrm{Fe}(\mathrm{Fe} / \mathrm{N} / \mathrm{C}) .^{5}$ A variety of Fe-containing species have been studied for ORR in alkaline electrolytes, including iron-nitrogen complexes, ${ }^{4,6}$ iron nitrides, ${ }^{7}$ iron carbides, ${ }^{8}$ iron oxides, 9 metallic iron, ${ }^{10}$ bimetallic compounds, $^{11}$ composites, ${ }^{12}$ and others. ${ }^{13}$ Progress has been made toward the synthesis methodologies of the aforementioned $\mathrm{Fe} / \mathrm{N} / \mathrm{C}$ catalysts and an understanding of their ORR characteristics, including the recognition of the essential role of a thermal treatment step and the strong dependence of ORR activity on the types of precursors and their concentrations to achieve the $\mathrm{Fe} / \mathrm{N} / \mathrm{C}$ system. ${ }^{14}$ The strong interaction between iron compounds and nitrogen-doped carbon substrates is also found beneficial to enhance the stability and reduction potential. $^{15}$ More recently, quite a few unique carbon nanostructures (i.e., nanotubes or core-shell morphology) catalyzed/directed by the in situ formed metallic nanoparticles/ templates have been demonstrated and advanced surface characterization techniques (i.e., X-ray absorption near-edge spectroscopy, XANES) have been adopted to identify the catalytic sites in the developed $\mathrm{Fe} / \mathrm{N} / \mathrm{C}$ catalysts. ${ }^{14}$

However, in spite of the above achievements, a key challenge remains that most of the reported activities of such NPMs catalysts have yet to match all the performance indicators of the equivalent PtC. ${ }^{5}$ On the other hand, apart from the cost issue,

Received: February 22, 2016

Revised: April 1, 2016

Published: April 27, 2016 
Scheme 1. Proposed Two-Step Design Principle for One-Pot Synthesis of Highly Efficient NPM ORR catalysts ${ }^{a}$

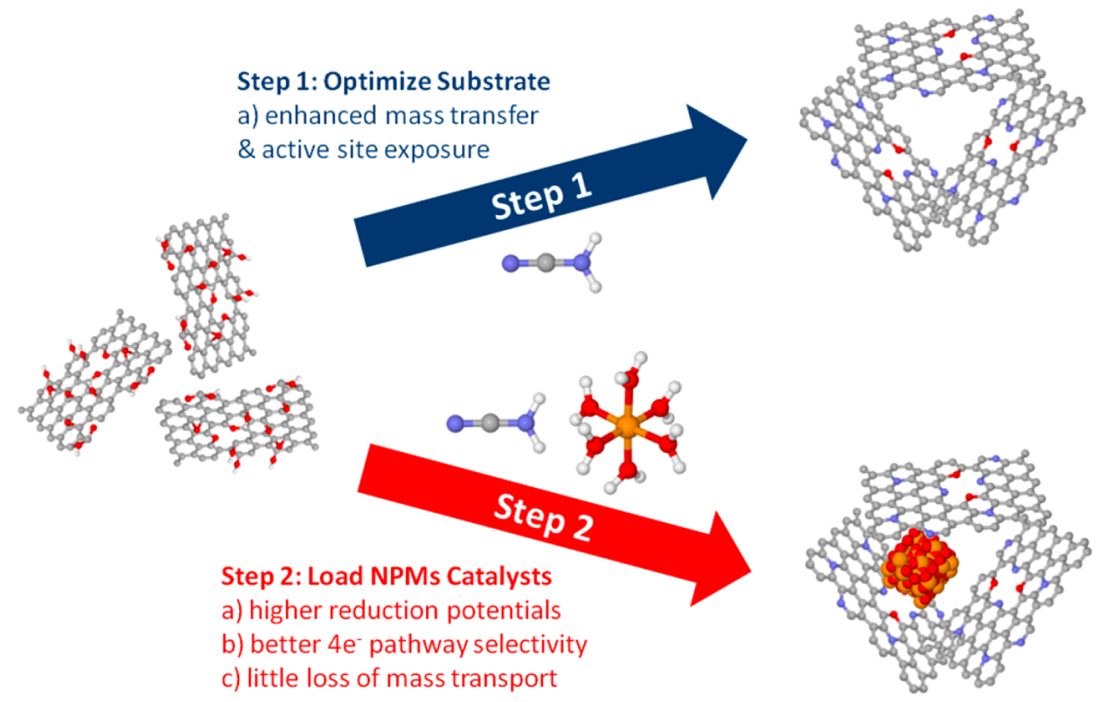

${ }^{a}$ Step 1 is to optimize in advance the conditions of $\mathrm{N}$ doping and hydrothermal synthesis, to achieve a highly porous support structure with an optimum $\mathrm{N}$ content, and, step 2 uses the optimized conditions to optimize the Fe precursor content, where the Fe precursor was added to the optimized support structure precursors in step 1 (but not to the previously formed structure!). The overall synthesis of the catalyst system is in one pot under the optimized conditions, followed by high-temperature calcinations.

the current PtC catalysts also suffer from several weaknesses: (1) poor mass transfer owing to the nonoptimized carbon substrate, ${ }^{16}(2)$ reduced number of electrons transferred in the mixed kinetic-diffusion region as a result of peroxide $\left(\mathrm{HO}_{2}{ }^{-}\right)$ formation on surface oxide, ${ }^{3}$ and (3) structural instability leading to dissolution of $\mathrm{Pt}$ during the ORR. ${ }^{17}$

Given that both chemical composition and structure are critically important for the ORR, a rational design of facile NPMs must optimally consider both properties. An ideal NPM catalyst should consist of (1) an optimized hierarchical substrate to ensure sufficient mass transfer and catalytic sites exposure, ${ }^{18}$ (2) active NPM catalytic sites with strong $\mathrm{HO}_{2}{ }^{-}$ binding to promote a four-electron $\left(4 \mathrm{e}^{-}\right)$transfer pathway ${ }^{3 \mathrm{~b}}$ and with oxygen adsorption kinetics comparable to that of $\mathrm{Pt}$ for enhanced onset reduction potential, ${ }^{19}$ and (3) strong and stable interaction between NPMs and the substrate for prolonged lifetime. ${ }^{15}$ In this regard, we propose a two-step design process for such highly efficient NPM catalysts: (1) hierarchical porosity of the supporting substrate is formed and optimized in advance, especially to achieve high total pore volume for rapid mass transfer, and (2) a suitable amount of NPM precursor is introduced into the optimized substrate under optimized conditions to form well-dispersed nanoparticles, so as to boost the reduction potential while maintaining the hierarchical nanostructure.

Herein we report a successful example of forming and confining phase-pure maghemite nanoparticles $\left(\gamma-\mathrm{Fe}_{2} \mathrm{O}_{3}\right.$, of an average particle size of $2.6 \pm 0.5 \mathrm{~nm}$ ) into a hierarchically porous nitrogen-doped graphene framework (Scheme 1). A porous graphene framework (GF_800) was adopted as the baseline substrate, since the hydrothermal self-assembly of graphene oxide can readily form a hierarchical nanostructure, with a substantial amount of micro-/mesopores (i.e., $<6 \mathrm{~nm}$ ) and large interconnected voids (i.e., $>1 \mu \mathrm{m}$ ). Such hierarchical porosity is optimized by adjustment of the concentration of a nitrogen precursor (GF+N2_800) and can be largely preserved after the addition of a small quantity of an iron precursor (GF $\left.+\mathrm{N} 2+\mathrm{Fe} 1 \_800\right)$. Furthermore, the nitrogen doping is expected to facilitate the anchoring and fixation of the more active iron compound on the substrate and thus to improve the stability of the proposed catalysts. ${ }^{15}$ The resulting porous graphene framework confined maghemite system, GF+N2+Fe1_800, surpasses the performance of the equivalent commercial $\overline{\mathrm{PtC}}$, in terms of more positive half-wave reduction potential (i.e., +27 $\mathrm{mV}$ at $3 \mathrm{~mA} \mathrm{~cm}{ }^{-2}$ ), significantly lower peroxide formation ratio (i.e., 0.31 vs $4.57 \%$ at $0.8 \mathrm{~V}$ vs $\mathrm{RHE}$ ), more than triple the kinetic current density (i.e., 34.3 vs $10.96 \mathrm{~mA} \mathrm{~cm}^{-2}$ at $0.8 \mathrm{~V}$ vs RHE), smaller Tafel slope (i.e., 66.3 vs $83.5 \mathrm{mV} \mathrm{dec}^{-1}$ ), and better durability (i.e., 3.8 vs $25.2 \%$ relative current loss after 20 $\mathrm{h}$ chronoamperometry test). To the best of our knowledge, the activity of this nanoconfined maghemite system is among the best of all the existing Fe-based ORR catalysts. More importantly, the same synthesis approach was applied to confine $\mathrm{Pt}$ nanoparticles and the resulting material, GF $+\mathrm{N} 2+\mathrm{Pt} 1$ 800, shows ORR behaviors nearly identical with those of the nanoconfined $\gamma-\mathrm{Fe}_{2} \mathrm{O}_{3}\left(\mathrm{GF}+\mathrm{N} 2+\mathrm{Fe} 1 \_800\right)$. This indicates that the proposed design principle should have wide applicability for optimization of ORR catalysis.

\section{EXPERIMENTAL SECTION}

2.1. Chemicals. The following chemicals were used as received without modification: graphite $(<20 \mu \mathrm{m}$, SigmaAldrich), sulfuric acid (95-97\%, Merck KGaA), potassium permanganate $(99+\%$, Sigma-Aldrich), hydrogen peroxide aqueous solution (30 wt \%, Sigma-Aldrich), iron(III) chloride hexahydrate (97\%, Sigma-Aldrich), chloroplatinic acid (Johnson Matthey), cyanamide aqueous solution (50 wt \%, SigmaAldrich), Nafion (5 wt \% in alcohol and water, Sigma-Aldrich), ethanol absolute (VWR), and $20 \%$ platinum on carbon black (Alfa Aesar).

2.2. Preparation of a Graphene Oxide Precursor Solution. Graphite oxide (GO) was prepared by a modified Hummer method, as previously reported. ${ }^{17}$ The graphene oxide aqueous solution $\left(2 \mathrm{mg} \mathrm{mL}^{-1}\right)$ was achieved by continuous probe sonication (Hielscher UP400) of a mixture of $1 \mathrm{~g}$ of GO and $500 \mathrm{~mL}$ of $\mathrm{DI} \mathrm{H}_{2} \mathrm{O}$ for $24 \mathrm{~h}$, followed by centrifugation 

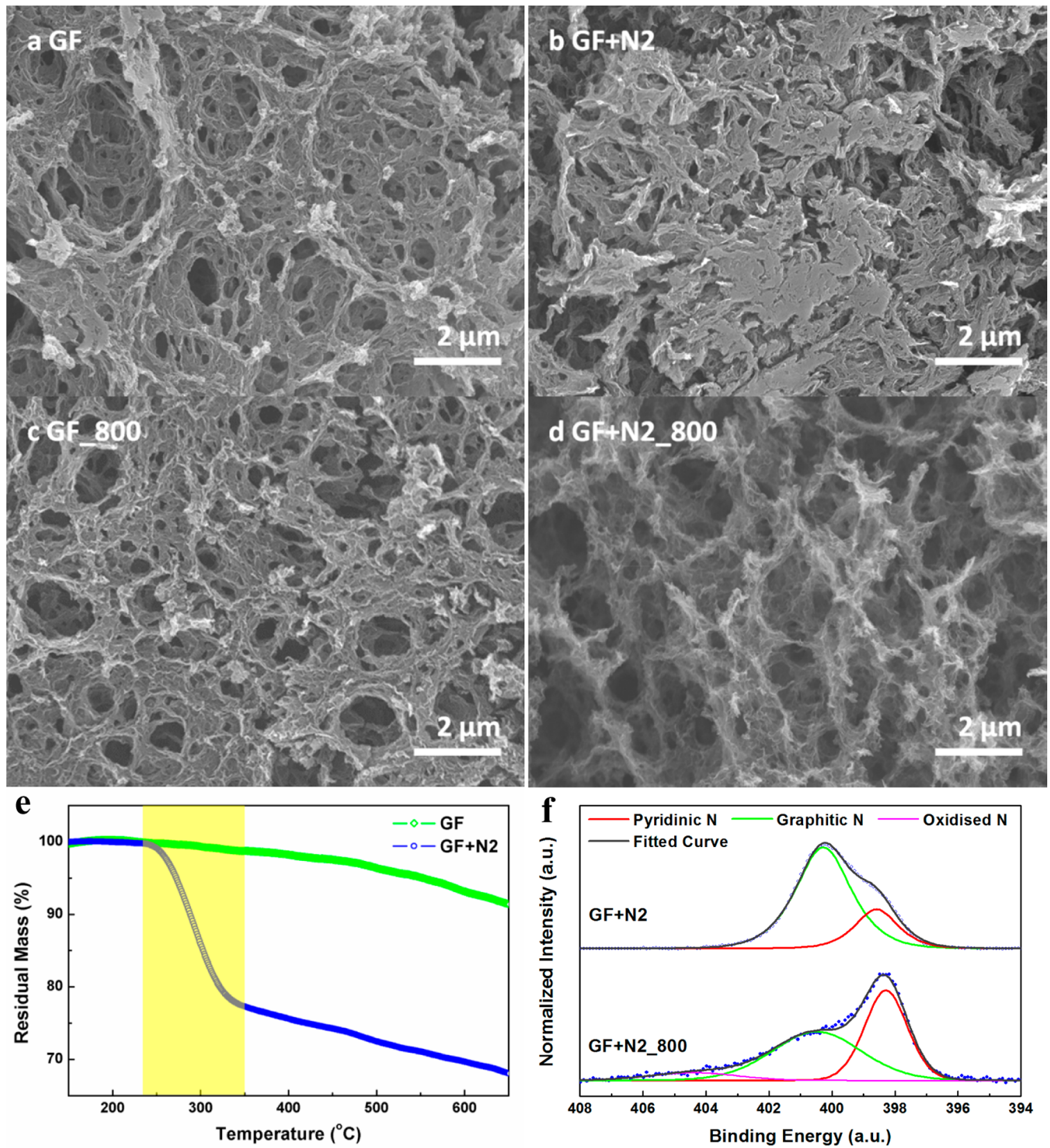

Figure 1. (a-d) SEM images of (a) GF, (b) GF+N2, (c) GF_800, and (d) GF+N2_800. (e) TGA of GF and GF+N2 under an $\mathrm{N}_{2}$ gas environment with a ramping rate of $3{ }^{\circ} \mathrm{C} \mathrm{min}^{-1}$. (f) XPS $\mathrm{N} 1$ s spectra for $\mathrm{GF}+\mathrm{N} 2$ and $\mathrm{GF}+\mathrm{N} 2 \_800$.

(Heraeus Biofuge Primo) at $8000 \mathrm{rpm}$ for $30 \mathrm{~min}$ to remove any trace amount of unexfoliated GO.

2.3. Preparation of Hierarchically Porous NitrogenDoped Graphene Framework and Confinement of Maghemite Nanoparticles. The overall synthesis approach is a one-pot hydrothermal reaction process, using a graphene oxide aqueous solution, cyanamide, and iron(III) chloride as precursors for the framework, the $\mathrm{N}$ doping, and maghemite nanoparticles, respectively, which is followed by freeze-drying and further thermal treatment. A control sample (GF_800) was first synthesized using $15 \mathrm{~mL}$ of a graphene oxide aqueous solution $\left(2 \mathrm{mg} \mathrm{mL}^{-1}\right)$. For optimization of $\mathrm{N}$ doping, to the same amount of graphene oxide solution was added 120, 240, or $600 \mu \mathrm{L}$ of an aqueous cyanamide solution (50 wt \%), hereafter named with the affix N1, N2, or N5, respectively. Finally the optimized composition from the above was used for further addition of $0.05,0.15$, or $0.25 \mathrm{mmol}$ of iron(III) chloride hexahydrate, $\mathrm{FeCl}_{3} \cdot 6 \mathrm{H}_{2} \mathrm{O}(13.5,40.5$, or $67.5 \mathrm{mg}$; hereafter named with the affix $\mathrm{Fe} 1, \mathrm{Fe} 3$, or $\mathrm{Fe} 5$, respectively). In all cases, the mixture was sonicated for $30 \mathrm{~min}$ before being moved into a Teflon-lined stainless steel autoclave for hydrothermal reaction at $180{ }^{\circ} \mathrm{C}$ for $12 \mathrm{~h}$. The formed hydrogel was freeze-dried for $24 \mathrm{~h}$ and then was thermally annealed at $800{ }^{\circ} \mathrm{C}$ for $1 \mathrm{~h}$ under flowing nitrogen (ramping rate was $\left.3{ }^{\circ} \mathrm{C} \mathrm{min}^{-1}\right)$. The obtained samples were thus named as $\mathrm{GF}+\mathrm{Nx}+\mathrm{Fey} \_800$ (values of $x$ and $y$ denote the ratios of the relevant precursors mentioned above). To understand the origin of porosity for the developed substrate, a doped graphene framework without high-temperature thermal treatment was also prepared for comparison and was named GF $+\mathrm{Nx}$. 
Table 1. Summary of BET SSA, Total Pore Volume, Elemental Ratio, and C 1s/N 1s Binding Configuration for GF+N and GF $+\mathbf{N} 800$

\begin{tabular}{|c|c|c|c|c|c|c|c|c|c|c|c|}
\hline \multirow[b]{2}{*}{ sample } & \multirow{2}{*}{$\frac{\text { BET }}{\text { SSA }\left(\mathrm{m}^{2} \mathrm{~g}^{-1}\right)}$} & \multirow[b]{2}{*}{$\mathrm{PV}\left(\mathrm{cc} \mathrm{g}^{-1}\right)$} & \multicolumn{3}{|c|}{ elemental anal. (atom \%) } & \multicolumn{3}{|c|}{ C 1s (atom \%) } & \multicolumn{3}{|c|}{$\mathrm{N}$ 1s (atom \%) } \\
\hline & & & $\mathrm{C}$ & $\mathrm{N}$ & $\mathrm{O}$ & $\mathrm{C}=\mathrm{C}$ & $\mathrm{C}-\mathrm{C}$ & $\mathrm{C}-\mathrm{O} / \mathrm{C}-\mathrm{N}$ & pyridinic & graphitic & $\overline{\text { oxidized }}$ \\
\hline $\mathrm{GF}+\mathrm{N} 0$ & 437.2 & 1.82 & 85.3 & & 14.8 & 71.4 & 17.4 & 11.2 & & & \\
\hline $\mathrm{GF}+\mathrm{N} 1$ & 244.7 & 1.20 & 75.2 & 12.3 & 12.5 & 59.5 & 19.2 & 21.4 & 16.8 & 83.2 & \\
\hline $\mathrm{GF}+\mathrm{N} 2$ & 229.8 & 1.22 & 71.7 & 15.0 & 13.3 & 56.9 & 21.0 & 22.1 & 23.1 & 76.9 & \\
\hline $\mathrm{GF}+\mathrm{N} 5$ & 258.6 & 1.45 & 67.0 & 19.6 & 13.4 & 63.6 & 19.9 & 26.4 & 33.2 & 66.8 & \\
\hline $\mathrm{GF}+\mathrm{N} 0 \_800$ & 598.9 & 2.13 & 94.4 & & 5.7 & 80.2 & 15.8 & 4.0 & & & \\
\hline $\mathrm{GF}+\mathrm{N} 1 \_800$ & 729.5 & 2.03 & 90.5 & 4.4 & 5.1 & 78.0 & 18.4 & 3.6 & 46.9 & 44.1 & 9.0 \\
\hline $\mathrm{GF}+\mathrm{N} 2 \_800$ & 741.2 & 3.62 & 88.4 & 5.5 & 6.1 & 75.7 & 18.8 & 5.6 & 43.3 & 49.1 & 7.6 \\
\hline $\mathrm{GF}+\mathrm{N} 5 \_800$ & 627.7 & 2.44 & 90.4 & 4.4 & 5.2 & 64.0 & 27.2 & 8.9 & 43.9 & 47.6 & 8.5 \\
\hline
\end{tabular}

2.4. Physical Characterizations. The morphology of samples was investigated by scanning electron microscopy and energy dispersive X-ray spectrometry (JEOL JSM-6301F) and transmission electron microscopy (JEOL 2100). Nitrogen sorption isotherms and BET surface areas were measured at 77 $\mathrm{K}$ with a Quantachrome Autosorb iQ-c. The chemical composition was analyzed by X-ray diffraction (STOE Stadi P), X-ray photon spectroscopy (Thermo Scientific K-Alpha), thermogravimetric analysis (Setaram Setsys 16/18), and Raman spectroscopy (Renishaw).

2.5. Electrochemical Characterizations. Rotating disk electrode (RDE) and rotating ring disk electrode (RRDE) measurements were conducted in $\mathrm{O}_{2}$-saturated $0.1 \mathrm{M} \mathrm{KOH}$. Oxygen was purged for at least $30 \mathrm{~min}$ before measurement and continuously bubbled through the electrolyte during the tests, in order to ensure the saturation of the electrolyte with $\mathrm{O}_{2}$. An $\mathrm{RDE}$ (glass carbon tip, Metrohm) or RRDE (Pt-ring/glassy carbon disk, Gamry) was used as the working electrode, $\mathrm{Ag}$ / $\mathrm{AgCl}$ (saturated $\mathrm{KCl}$, Metrohm) as the reference electrode, and a platinum sheet (Metrohm) as the counter electrode. The scan rate for rotating voltammetry was $10 \mathrm{mV} \mathrm{s}^{-1}$, and the ring potential was constant at $0.5 \mathrm{~V}$ vs $\mathrm{Ag} / \mathrm{AgCl}$. All results were recorded using Metrohm Autolab 302N and Metrohm Multi Autolab instruments. The potentials reported in this work were converted with reference to the reversible hydrogen electrode (RHE) scale by the addition of a value of $0.965 \mathrm{~V}$.

For preparation of the RDE working electrode, $4 \mathrm{mg}$ of the catalyst and $40 \mu \mathrm{L}$ of Nafion solution ( 5 wt \%) were added to 3 $\mathrm{mL}$ of deionized water, followed by sonication for $60 \mathrm{~min}$ to achieve uniform dispersion of the catalysts in the solvent. The catalyst suspension $(5.4 \mu \mathrm{L})$ was drop-casted on the RDE tip (3 $\mathrm{mm}$ diameter) and dried at $60{ }^{\circ} \mathrm{C}$. For RRDE working electrode preparation, $4 \mathrm{mg}$ of the catalyst and $40 \mu \mathrm{L}$ of Nafion solution (5 wt \%) were added to a mixture of $3 \mathrm{~mL}$ of deionized water and $1 \mathrm{~mL}$ of ethanol absolute, and $25 \mu \mathrm{L}$ of the catalyst suspension was then drop-casted on the RRDE tip electrode ( $5.61 \mathrm{~mm}$ diameter for GC). The catalyst loading is ca. $0.1 \mathrm{mg} \mathrm{cm}^{-2}$ for all samples, including commercial platinumloaded carbon.

For RDE, the electron transfer number (ETN, $n$ ) was calculated on the basis of the Koutecky-Levich (K-L) equation:

$$
\frac{1}{J}=\frac{1}{J_{\mathrm{L}}}+\frac{1}{J_{\mathrm{K}}}=\frac{1}{0.2 n F C_{0} D_{0}^{2 / 3} v^{-1 / 6} \omega^{1 / 2}}+\frac{1}{J_{\mathrm{K}}}
$$

where $J$ is the measured current density, $J_{\mathrm{L}}$ and $J_{\mathrm{K}}$ are the diffusion-limited and kinetic current densities, respectively, $F$ is the Faraday constant (96485 sA mol ${ }^{-1}$ ), $C_{0}$ is the bulk concentration of dissolved $\mathrm{O}_{2}$ in $0.1 \mathrm{M} \mathrm{KOH}\left(1.2 \times 10^{-3} \mathrm{~mol}\right.$ $\left.\mathrm{L}^{-1}\right), D_{0}$ is the diffusion coefficient of $\mathrm{O}_{2}$ in $0.1 \mathrm{M} \mathrm{KOH}(1.9 \times$ $\left.10^{-5} \mathrm{~cm}^{2} \mathrm{~s}^{-1}\right), v$ is the kinematic viscosity of the electrolyte $\left(0.01 \mathrm{~m}^{2} \mathrm{~s}^{-1}\right)$, and $\omega$ is the angular velocity (in $\mathrm{rpm}$ ).

For RRDE, the ETN was determined by the ratio of current density for ring/disk electrode using the equation

$$
n=4 \frac{I_{\mathrm{d}}}{I_{\mathrm{d}}+I_{\mathrm{r}} / N}
$$

where $I_{\mathrm{d}}$ and $I_{\mathrm{r}}$ are the measured currents for disk and ring electrodes, respectively, and $N$ is the current collection efficiency of the Pt ring (0.37). The potential of the ring electrode was kept at $0.5 \mathrm{~V}$ vs $\mathrm{Ag} / \mathrm{AgCl}$.

For the Tafel plot, the diffusion-corrected kinetic current density $\left(J_{\mathrm{K}}\right)$ was calculated on the basis of the K-L equation:

$$
J_{\mathrm{K}}=\frac{J J_{\mathrm{L}}}{J_{\mathrm{L}}-J}
$$

Electrode impedance spectroscopy (EIS) measurements were conducted at $1600 \mathrm{rpm}$ and at the potential under which the current density reaches $3 \mathrm{~mA} \mathrm{~cm}{ }^{-2}$ for each sample. The frequency range was $1 \mathrm{MHz}$ to $0.01 \mathrm{~Hz}$. The amplitude was $10 \mathrm{mV}$.

Chronoamperometry measurements were conducted at 1600 rpm and at the potential under which the current density reaches $3 \mathrm{~mA} \mathrm{~cm}^{-2}$ for each sample and lasted for $20 \mathrm{~h}$. The durability was further assessed by cyclic tests of the catalysts between 0.2 and $1.2 \mathrm{~V}$ vs RHE at $100 \mathrm{mV} \mathrm{s}^{-1}$ up to 5000 cycles. $^{20}$

Electrode evaluation was conducted in 0.1 and $6 \mathrm{M} \mathrm{O}_{2}$ saturated $\mathrm{KOH}$ electrodes. The electrodes were prepared by spray-coating the corresponding catalysts on carbon fiber paper gas diffusion layer (GDL, Ion Power). The loading ratio was 0.7 $\mathrm{mg} \mathrm{cm}{ }^{-2}$.

\section{RESULTS AND DISCUSSION}

3.1. Formation of Highly Porous N-Doped Graphene Framework. As the first step of the synthesis approach is to produce an optimized porous substrate, characteristics of the porosities of the synthesized samples were first compared from the scanning electron microscopy images (SEM) (Figure 1ad). An evident hierarchical structure (pore size ranging from ca. 0.5 to $1.5 \mu \mathrm{m}$ ) is shown in the SEM image of GF (Figure 1a), but such porous characteristics can hardly been seen in GF+N2 (Figure $1 \mathrm{~b}$ ). After thermal annealing, no apparent difference is observed between the morphologies of GF and GF_800 

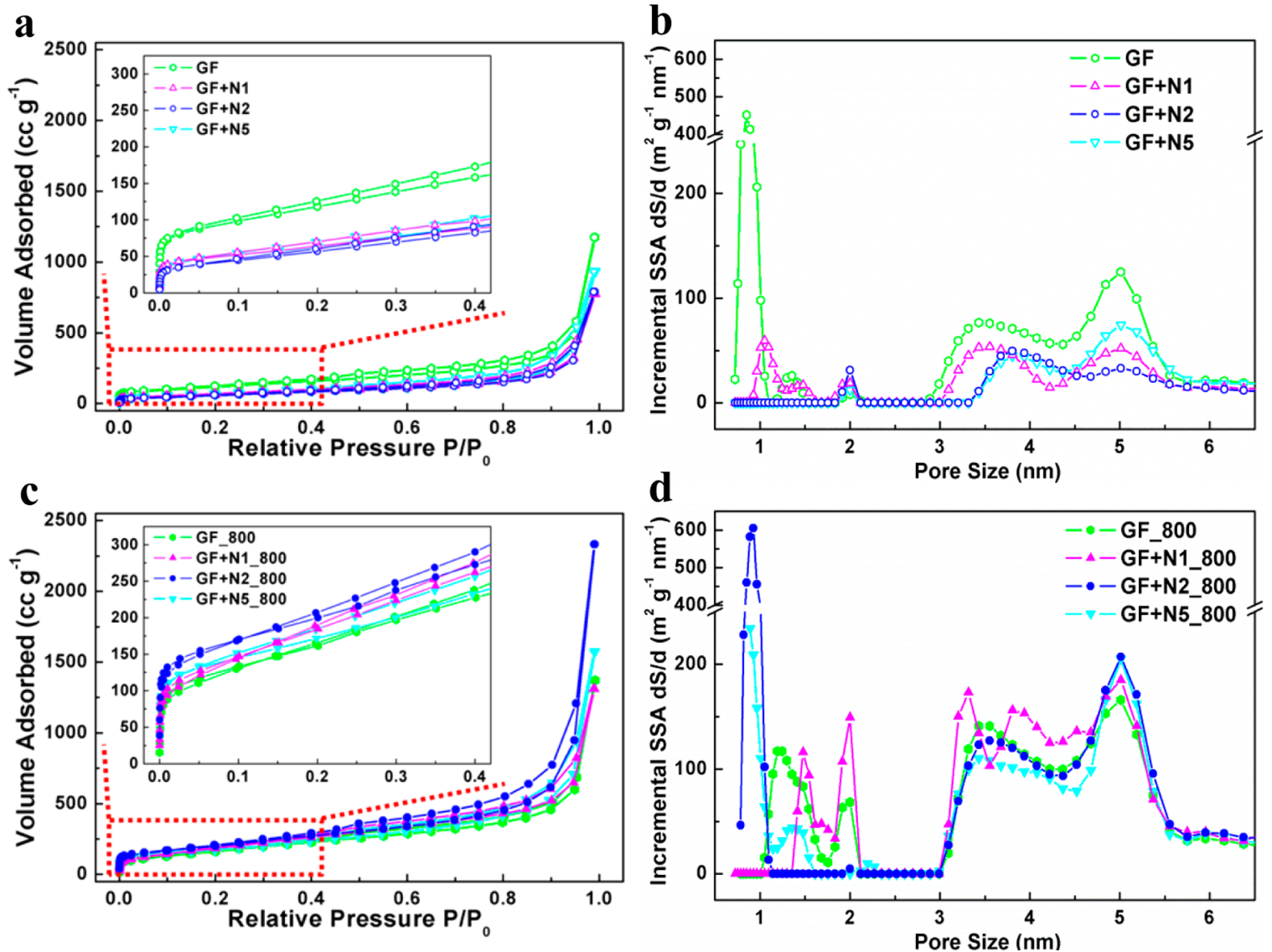

Figure 2. $\mathrm{N}_{2}$ adsorption/desorption isotherms at $77 \mathrm{~K}$ (left) and the corresponding PSD (right) calculated by the QSDFT model for (a, b) GF+N and (c, d) GF+N_800.

(Figure 1c), implying that the high-temperature treatment changes little of their macroscopic porosity. However, GF $+\mathrm{N} 2$ _800 exhibits a more hollow structure with larger interconnected voids (ca. $>2 \mu \mathrm{m}$, Figure 1d) after thermal annealing. The distinct morphology of GF+N2 and GF $+\mathrm{N} 2 \_800$ suggests that, during the hydrothermal reaction, the nitrogen precursors are "attached" to the graphene surface and block most of the pores; such nitrogen species are partially removed from and partially doped into the graphene framework in the following thermal treatment, during which the structure of the graphene framework is severely etched.

The removal of attached nitrogen species was probed by thermal gravimetric analysis (TGA) (Figure 1e). It is seen that an extra-sharp decrease of mass occurs between 230 and 350 ${ }^{\circ} \mathrm{C}$ for $\mathrm{GF}+\mathrm{N} 2$, in comparison with the continuous but slow mass loss for GF as the temperature increases. The nitrogen doping process was demonstrated through the transformation from the predominantly graphitic $\mathrm{N}$ of $\mathrm{GF}+\mathrm{N} 2$ to the pyridinic $\mathrm{N}$ of GF+N2_800, as shown by X-ray photoelectron spectroscopy (XPS) (Figure 1f). Both the concentration and the type of doped-N sites influence the electrochemical properties of the materials. Despite the debate on the exact role of N-doped sites, pyridinic $\mathrm{N}$ is generally regarded as responsible for the catalytic ORR activity, especially for the onset reduction potential, while graphitic $\mathrm{N}$ is believed to be beneficial to the electrical conductivity. ${ }^{21}$ Since those GF+N_800 samples show similar nitrogen contents and binding configurations (Table 1 ), it is reasonable to attribute the major improvement in performance to their different porous structures.
The porosity of each substrate was further investigated by nitrogen adsorption-desorption isotherms at $77 \mathrm{~K}$ (Figure $2 \mathrm{a}, \mathrm{c})$. It is shown that all the $\mathrm{GF}+\mathrm{N}$ and $\mathrm{GF}+\mathrm{N} \_800$ samples possess a hierarchically porous nanostructure, featuring an initial adsorption for micropores (i.e., $P / P_{0}<0.01$ ), a hysteresis loop for mesopores (i.e., $P / P_{0}>0.4$ ), and a long "tail" for large macropores/voids (i.e., the highest $P / P_{0}$ ). It is also seen that the $\mathrm{N}_{2}$ sorption for $\mathrm{GF}+\mathrm{N}$ is generally lower than that for GF, while GF+N_800 possess higher sorption than GF_800. The corresponding pore size distribution (PSD, Figure $2 \mathrm{~b}, \mathrm{~d}$ ) calculated by the QSDFT (quenched solid density functional theory) model illustrates that, for GF and GF_800, the thermal "etching" (as confirmed by TGA) removes the residual oxygen functional group on the graphene surface and turns those small micropores $(0.8-1 \mathrm{~nm})$ into relatively large pores $(1-2 \mathrm{~nm})$ and even mesopores $(3-6 \mathrm{~nm})$. With regard to $\mathrm{GF}+\mathrm{N}$ and $\mathrm{GF}$ $+\mathrm{N}$ 800, the addition of nitrogen precursors during the hydrothermal reaction blocks most of the micro-/mesopores as discussed above; the following thermal annealing not only reopens those pores but also generates a large number of new structural defects.

The GF+N_800 samples generally show a higher BrunauerEmmett-Teller specific surface area (BET SSA) and/or total pore volume (PV) in comparison to GF_800 (Table 1). It is noted that the concentration of the nitrogen precursor is crucial to optimize the hierarchical porosity: when it is too low, it cannot block all the attachable sites during the hydrothermal reaction, but when it is too high, it hampers the subsequent thermal etching (Figure 2b,d). Therefore, GF+N2_800, with an intermediate concentration of the nitrogen precursor, possesses 
a
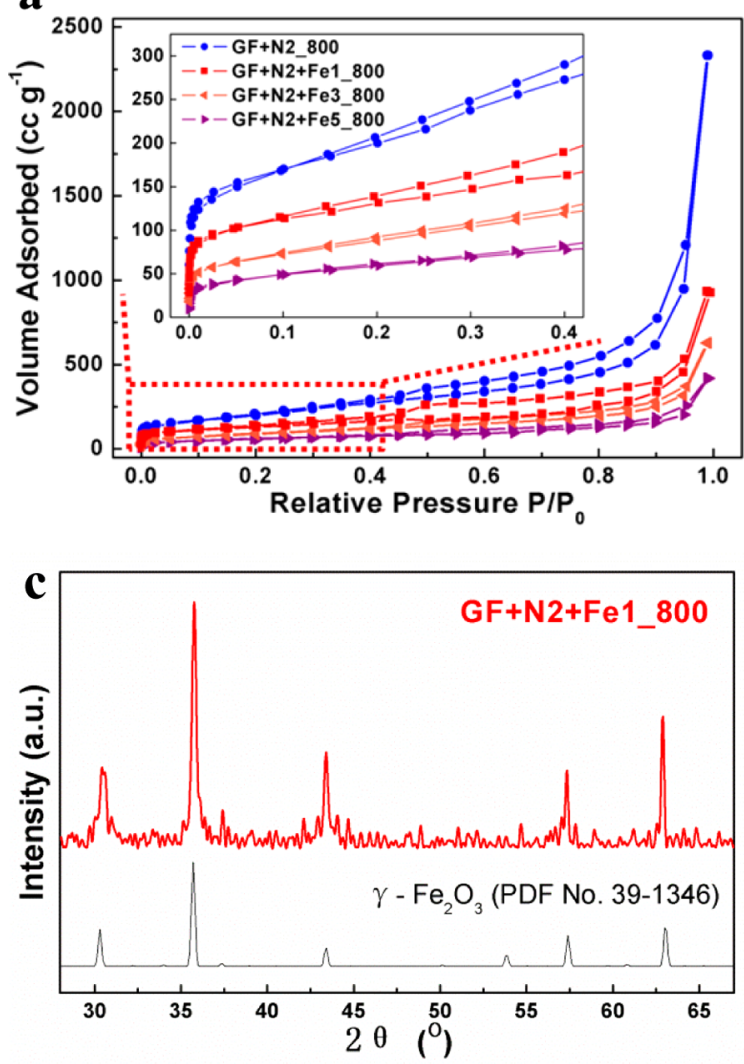

b
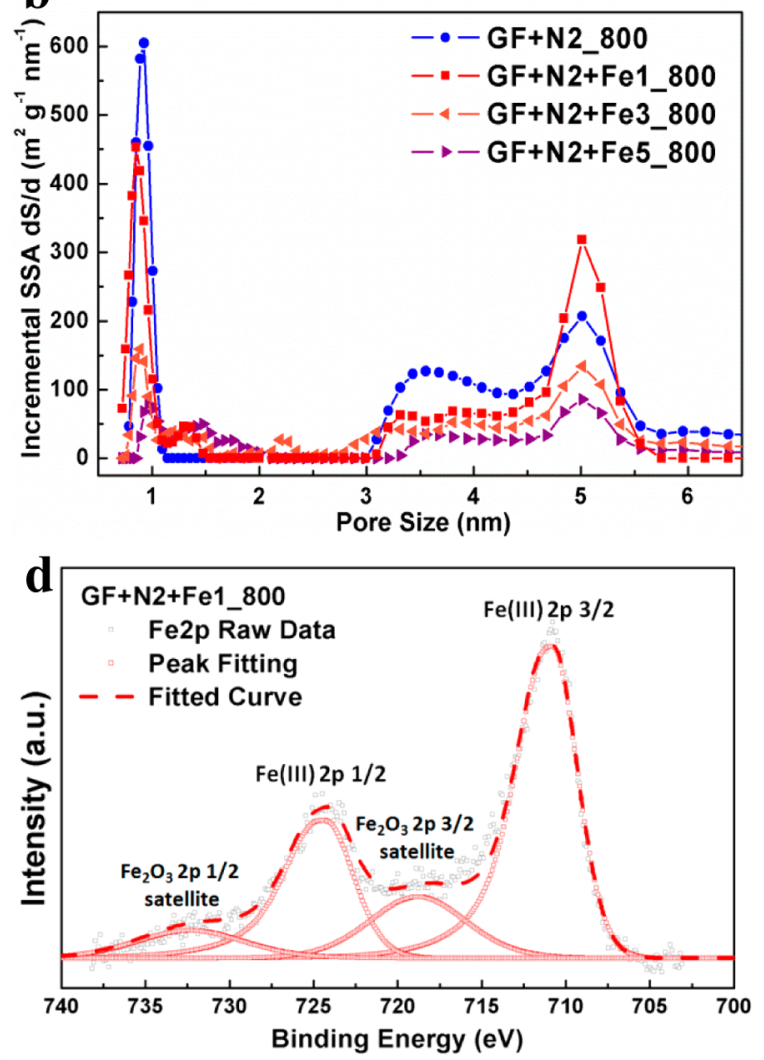
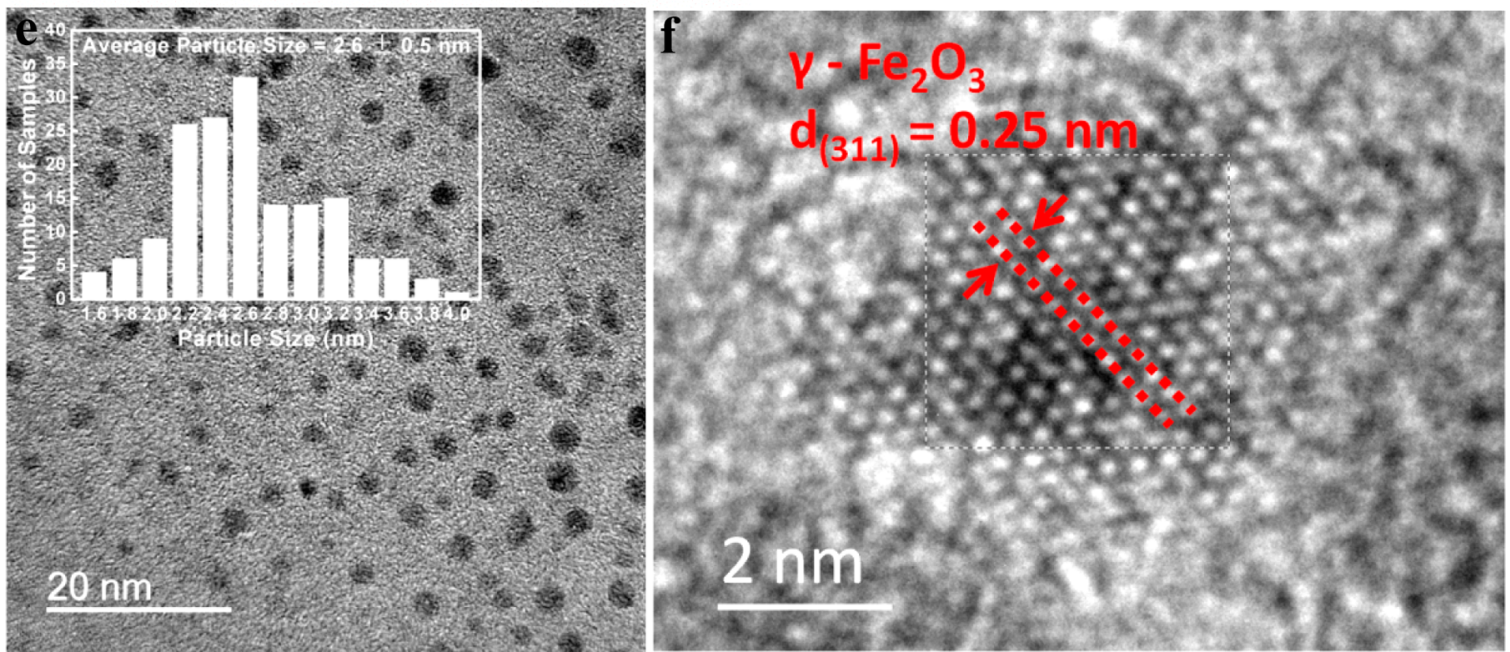

Figure 3. (a) $\mathrm{N}_{2}$ sorption isotherms at $77 \mathrm{~K}$ and (b) the corresponding PSD calculated for $\mathrm{GF}+\mathrm{N}+\mathrm{Fe} 800$. (c) XRD pattern of GF+N2+Fe1 800 , in comparison with the standard $\gamma-\mathrm{Fe}_{2} \mathrm{O}_{3}$ reference. (d) XPS Fe 2p spectrum of GF+N2+Fe1_800 and TEM images of GF+N2+Fe1_800 under (e) low and (f) high magnification. The insert in (e) is the particle size distribution of $\gamma-\mathrm{Fe}_{2} \mathrm{O}_{3}$.

the highest BET SSA of $741.2 \mathrm{~m}^{2} \mathrm{~g}^{-1}$ and PV of $3.62 \mathrm{cc} \mathrm{g}^{-1}$. The surprisingly large total PV (almost double the value of the rest of the GF+N_800 samples) is believed to be favorable for rapid mass transfer during the ORR.

3.2. Nanoconfinement of Maghemite Catalysts. The second step of the proposed design principle is to load an appropriate amount of NPM catalysts in the optimized substrate. The influence of NPM concentration on the overall porosity was studied through $\mathrm{N}_{2}$ sorption isotherms (Figure $3 a$ ), and it is shown that the $\mathrm{N}_{2}$ sorption for GF+N2+Fe 800 decreases as the $\mathrm{Fe}$ ratio increases. The large reduction in the micro-/mesoporosity of GF+N2+Fe_800 (Figure 3b) confirms that most of the Fe compounds have been successfully confined into the porous $\mathrm{GF}+\mathrm{N} 2 \_800$. What is more, adding the same amount of $\mathrm{Fe}$ compound to GF+N1_800 gives a considerably smaller SSA and PV of $\mathrm{GF}+\mathrm{N} 1+\mathrm{Fe}_{\overline{1}}-800$ in comparison to those of $\mathrm{GF}+\mathrm{N} 2+\mathrm{Fe} 1 \_800$ (Table $\overline{\mathrm{S}} 1$ in the Supporting Information), clearly pointing out the importance of a preoptimized substrate for the nanostructure of the final GF $+\mathrm{N}+\mathrm{Fe} 800$.

The chemical composition of the Fe-containing species was first characterized by X-ray diffraction (XRD) (Figure 3c), and it is shown that the XRD pattern of $\mathrm{GF}+\mathrm{N} 2+\mathrm{Fe} 1800$ fits perfectly with the standard $\gamma-\mathrm{Fe}_{2} \mathrm{O}_{3}$ reference. ${ }^{22}$ Note that maghemite has almost the same crystal structure as magnetite $\left(\mathrm{Fe}_{3} \mathrm{O}_{4}\right)$; X-ray photoelectron spectroscopy (XPS) was further 
a

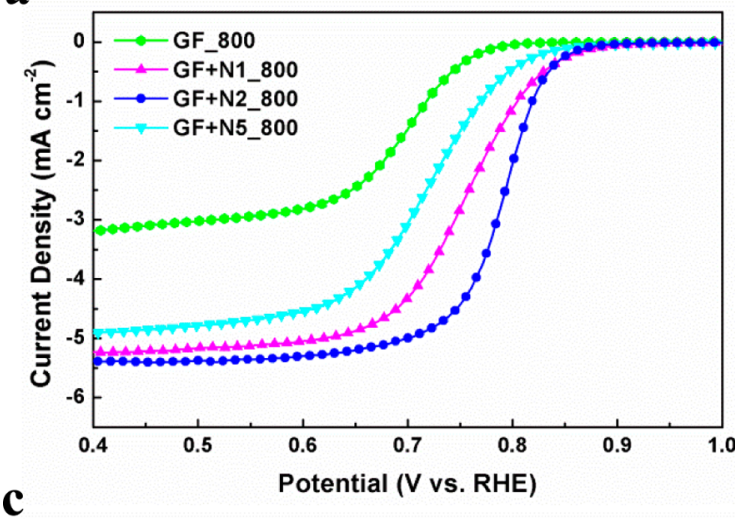

c

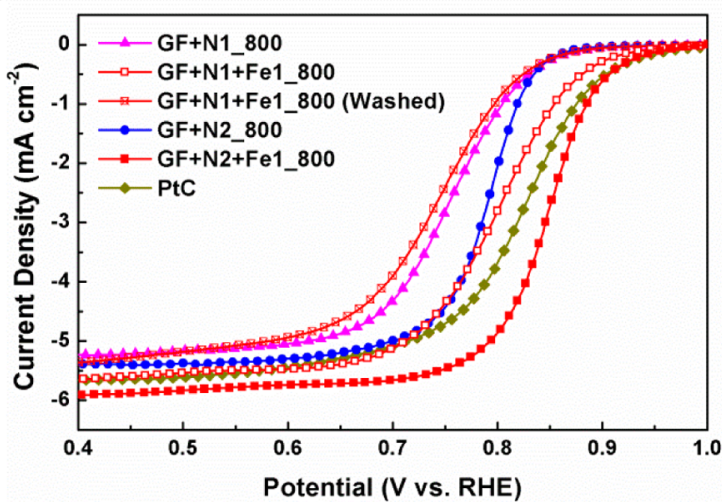

b
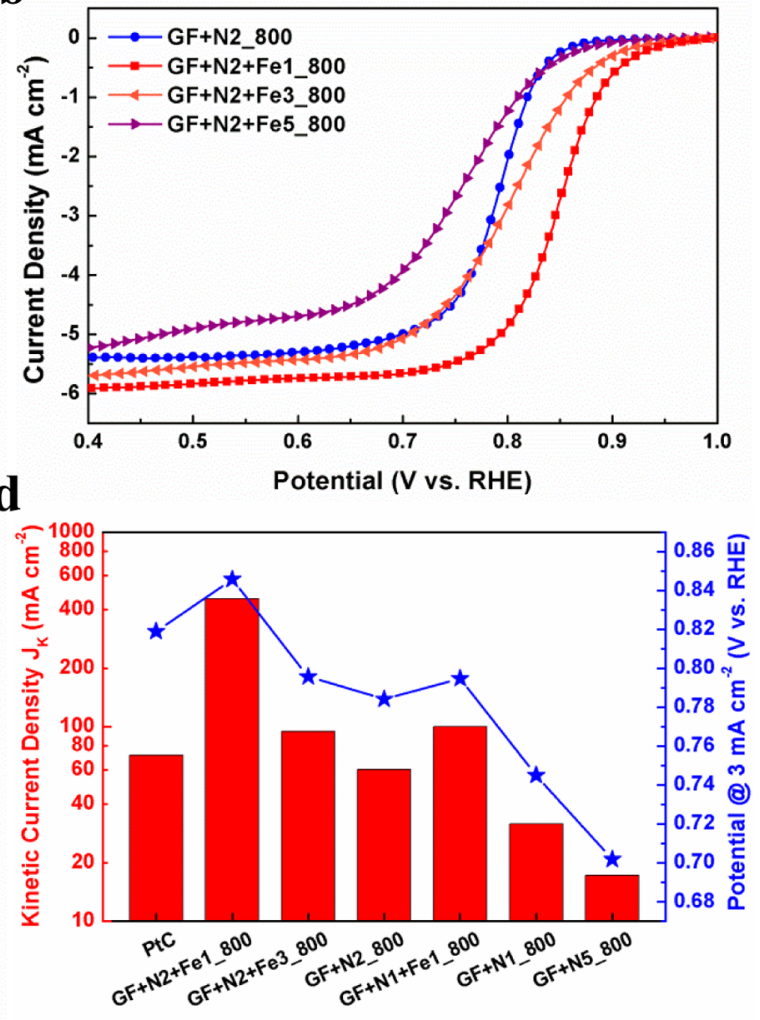

Figure 4. RDE LSV plots of GF+N+Fe_800 at 1600 rpm: (a) effect of nitrogen precursor concentration for substrates; (b) effect of iron precursor concentration on the optimized substrate; (c) effect of substrates/NPMs and comparison with commercial PtC. (d) Comparison of kinetic current density $J_{\mathrm{K}}$ at $0.65 \mathrm{~V}$ vs $\mathrm{RHE}$ and potential $V$ at $3 \mathrm{~mA} \mathrm{~cm}{ }^{-2}$.

adopted to differentiate those two phases. It is shown in the XPS Fe $2 \mathrm{p}$ spectrum of GF+N2+Fe1 (Figure $3 \mathrm{~d}$ ) that the peaks centered at 710.8 and $724.3 \mathrm{eV}$ represent $\mathrm{Fe}(\mathrm{III}) 2 \mathrm{p}_{3 / 2}$ and $2 \mathrm{p}_{1 / 2}$, respectively, and no $\mathrm{Fe}(\mathrm{II})$ or metallic $\mathrm{Fe}$ peak is observed (i.e., 709.6 or $706.7 \mathrm{eV}$ for $\mathrm{Fe}(\mathrm{II})$ or $\mathrm{Fe}(0) 2 \mathrm{p}_{3 / 2}$ ). In addition, the satellite $\mathrm{Fe} 2 \mathrm{p}_{3 / 2}$ peak at $718.8 \mathrm{eV}$ is characteristic of $\mathrm{Fe}_{2} \mathrm{O}_{3}$, while for $\mathrm{Fe}_{3} \mathrm{O}_{4}$ the satellite peak is generally within ca. $715-716 \mathrm{eV}^{23}$ Therefore, it is evident that $\gamma-\mathrm{Fe}_{2} \mathrm{O}_{3}$ is the only iron compound in $\mathrm{GF}+\mathrm{N}+\mathrm{Fe} \_800$, from both XRD and XPS observations. Moreover, the peak position of pyridinic $\mathrm{N}$ in $\mathrm{GF}+\mathrm{N} 2+\mathrm{Fe} 800$ is $\mathrm{ca} .0 .2-0.3 \mathrm{eV}$ more positive than that for GF+N2_800 (Figure S1b in the Supporting Information), which indicates the interaction between $\gamma-\mathrm{Fe}_{2} \mathrm{O}_{3}$ and the nitrogen-doped graphene framework. ${ }^{6 \mathrm{f}}$

The morphology of the $\gamma-\mathrm{Fe}_{2} \mathrm{O}_{3}$ nanoparticles was studied by transmission electron microscopy (TEM) (Figure 3e,f). It is seen in the TEM of GF+N2+Fe1_800 (Figure 3e) that the $\gamma$ $\mathrm{Fe}_{2} \mathrm{O}_{3}$ nanospheres with an average particle size of $2.6 \pm 0.5$ $\mathrm{nm}$ are uniformly dispersed over the nitrogen-doped graphene. The nanoparticles in the high-resolution TEM image (Figure 3f) display a $d$ spacing of $\sim 2.5 \AA$, in good agreement with that of the (311) planes of the $\gamma-\mathrm{Fe}_{2} \mathrm{O}_{3}$ phase (corresponding to the XRD peak position at $2 \theta=35.4^{\circ}$, Figure $3 \mathrm{c}$ ).

3.3. Comparison of Catalytic Activities. The catalytic ORR activities were studied through linear sweep voltammograms (LSVs) at $1600 \mathrm{rpm}$ using the rotating disk electrode technique (RDE), (Figure $4 a-c)$. The performance of different substrates was first compared (Figure $4 \mathrm{a}$ ), and it is seen that the onset reduction potentials of $\mathrm{GF}+\mathrm{N} \_800$ are $70-100 \mathrm{mV}$ higher than that of GF_800. In addition, the limiting current densities of GF+N1_800, GF+N2_800, and GF+N5_800 reach
5.24, 5.40, and $4.91 \mathrm{~mA} \mathrm{~cm}^{-2}$, respectively, indicating a $4 \mathrm{e}$ transfer pathway, while GF_800 possesses a value of $3.18 \mathrm{~mA}$ $\mathrm{cm}^{-2}$, which is closer to the $2 \mathrm{e}$ pathway. The improved reduction potentials and 4e pathway selectivity of GF+N_800 demonstrate their better oxygen and peroxide adsorption capability derived from the nitrogen doping. ${ }^{24}$ Note that GF $+\mathrm{N} 2 \_800$ shows a similar onset but superior half-wave reduction potential, in comparison with GF+N1 800, which should be attributed to rapid mass transfer as a result of the ultralarge pore volume of $\mathrm{GF}+\mathrm{N} 2 \_800$. The slightly smaller onset potential and limiting current density of GF+N5_800 in comparison to those of the other two $\mathrm{GF}+\mathrm{N} \_800$ samples is probably due to its lower conductivity (lower $\overline{\mathrm{sp}}^{2}$ carbon ratio, Table 1).

The effect of the $\gamma-\mathrm{Fe}_{2} \mathrm{O}_{3}$ loading ratio was then investigated by the confinement of three different concentrations of $\gamma-\mathrm{Fe}_{2} \mathrm{O}_{3}$ on the best substrate, GF+N2_800 (Figure 4b). GF $+\mathrm{N} 2+\mathrm{Fe} 1800$ shows a similar onset but much improved half-wave reduction potential, in comparison with GF $+\mathrm{N} 2+\mathrm{Fe} 3$ _800. This can be explained by the better mass transfer of $\mathrm{GF}+\mathrm{N} 2+\mathrm{Fe} 1$ 800, since the higher loading of $\gamma$ $\mathrm{Fe}_{2} \mathrm{O}_{3}$ affects more the overall porosity. A further increase of $\gamma$ $\mathrm{Fe}_{2} \mathrm{O}_{3}$ loading even reduces the onset potential (i.e., GF $+\mathrm{N} 2+\mathrm{Fe} 5$ 800), suggesting that no more $\gamma-\mathrm{Fe}_{2} \mathrm{O}_{3}$ can be confined in the porous structure of $\mathrm{GF}+\mathrm{N} 2 \_800$ and the extra groups are merely attached on the surface. The almost identical gaps between the onset and half-wave potential of GF $+\mathrm{N} 2+\mathrm{Fe} 1800$ and $\mathrm{GF}+\mathrm{N} 2800$ demonstrate that nanoconfinement of a controllable amount of NPMs into a hierarchical substrate causes affordable reduction of its porosity, 
a

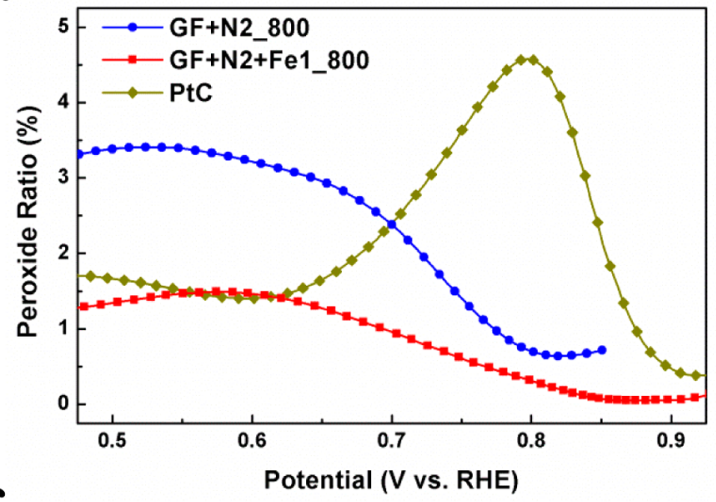

C

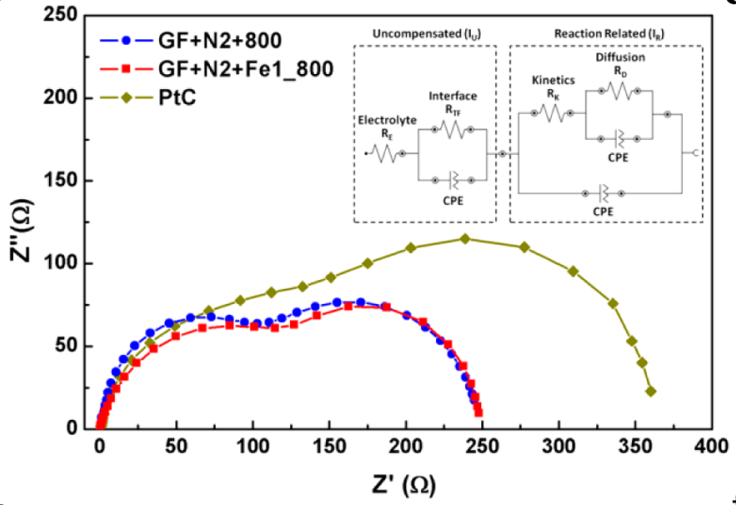

e

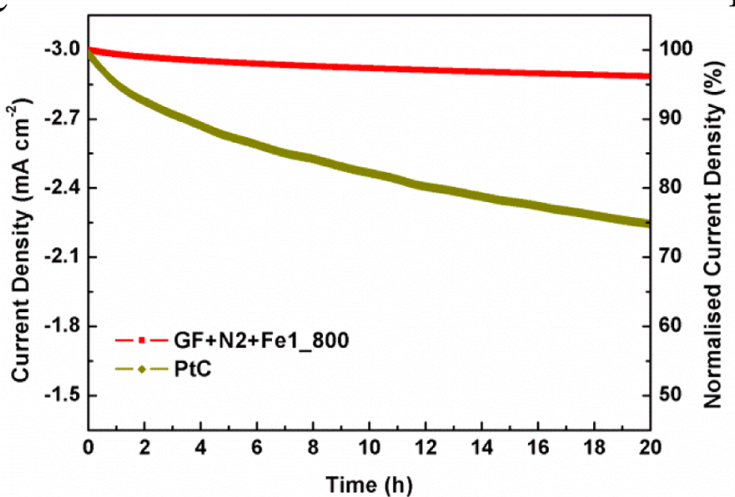

b

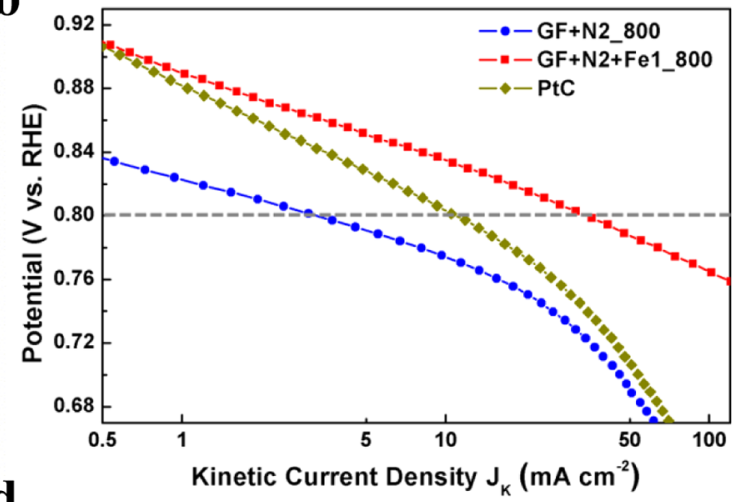

d
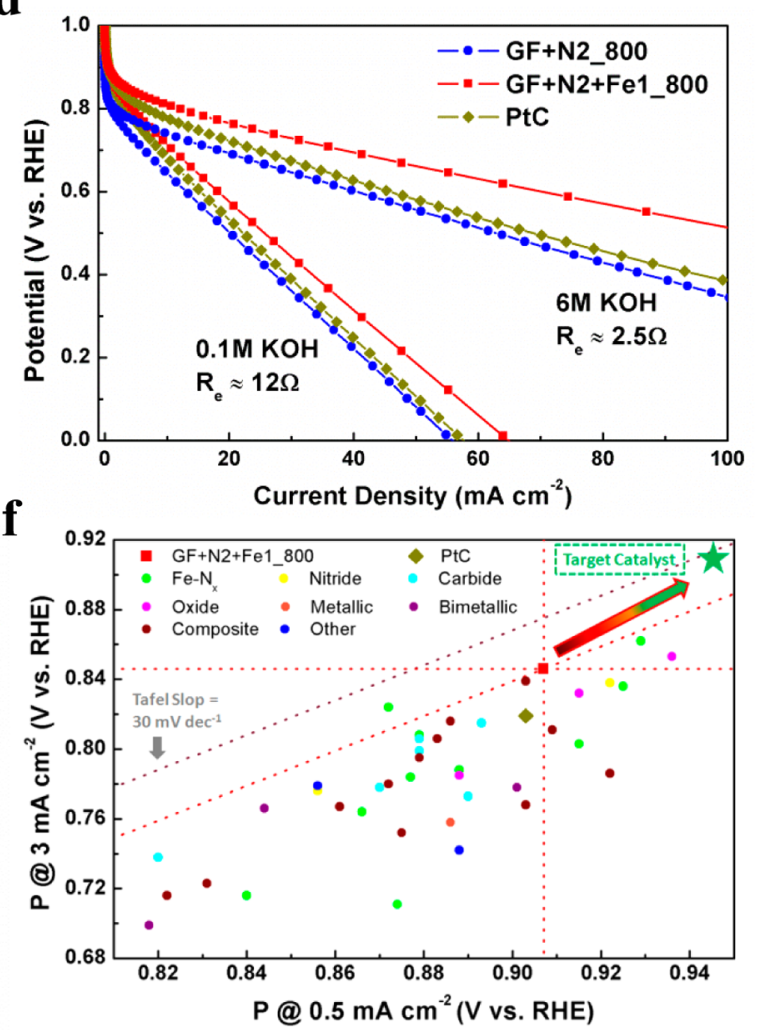

Figure 5. $(\mathrm{a}-\mathrm{d}$ ) Comparison of ORR activities among GF+N2 800, GF+N2+Fe 800 and PtC: (a) peroxide formation ratio; (b) Tafel plot; (c) EIS Nyquist plot; (d) corresponding electrode performance. (e) Chronoamperometry of GF+N2+Fe1_800 and PtC. (f) Comparison of the catalytic activity of GF+N2+Fe1_800 with those of other Fe-based catalysts.

leading to considerable improvement in reduction potential but negligible loss of its mass transfer capability.

To further demonstrate the significance of a preoptimized hierarchically porous substrate, the optimal amount of $\gamma-\mathrm{Fe}_{2} \mathrm{O}_{3}$ was loaded into different substrates (Figure 4c). It can be seen that the distinction between the ORR activities of GF $+\mathrm{N} 2+\mathrm{Fe} 1 \_800$ and $\mathrm{GF}+\mathrm{N} 1+\mathrm{Fe} 1 \_800$ follows the same pattern between $\overline{\mathrm{GF}}+\mathrm{N} 2 \_800$ and $\mathrm{GF}+\mathrm{N} 1 \_800$, revealing that the enhancement in activity should be mainly because of the better substrate. Moreover, the similar performances between GF $+\mathrm{N} 1+\mathrm{Fe} 1$ 800_W $\left(\gamma-\mathrm{Fe}_{2} \mathrm{O}_{3}\right.$ is removed by acid washing $)$ and $\mathrm{GF}+\mathrm{N} 1 \_800$ prove that $\gamma-\mathrm{Fe}_{2} \mathrm{O}_{3}$ must be responsible for the better onset potential. As a result, the obtained GF $+\mathrm{N} 2+\mathrm{Fe} 1800$ shows a higher reduction potential than the commercial PtC (i.e., $+27 \mathrm{mV}$ at $3 \mathrm{~mA} \mathrm{~cm}^{-2}$ ).

$\mathrm{GF}+\mathrm{N} \_800, \mathrm{GF}+\mathrm{N}+\mathrm{Fe} \_800$, and $\mathrm{PtC}$ all unsurprisingly possess an electron transfer number $(\mathrm{ETN})$ of 4 at $0.65 \mathrm{~V}$ vs
RHE, calculated from the Koutecky-Levich (K-L) plot (Figure S3 in the Supporting Information). However, their kinetics current densities $J_{\mathrm{K}}$ at the same potential (also derived from the $\mathrm{K}-\mathrm{L}$ plots) and the half-wave potentials (V vs RHE at $3 \mathrm{~mA}$ $\mathrm{cm}^{-2}$ ) are quite distinct (Figure $4 \mathrm{~d}$ ), which is due to a combined effect of different porous substrates and $\gamma-\mathrm{Fe}_{2} \mathrm{O}_{3} / \mathrm{Pt}$ catalysts. Note that, at $0.65 \mathrm{~V}$ vs RHE, not only the $J_{\mathrm{K}}$ value of $\mathrm{GF}+\mathrm{N} 2+\mathrm{Fe} 1 \_800\left(454.55 \mathrm{~mA} \mathrm{~cm}{ }^{-2}\right)$ is 5 times higher than that of PtC $\left(71 \mathrm{~mA} \mathrm{~cm}^{-2}\right)$ but also $\mathrm{GF}+\mathrm{N} 2+\mathrm{Fe} 38800$ (94.34 $\left.\mathrm{mA} \mathrm{cm}{ }^{-2}\right)$ and $\mathrm{GF}+\mathrm{N} 1+\mathrm{Fe} 1 \_800\left(99.90 \mathrm{~mA} \mathrm{~cm}{ }^{-2}\right)$ can also surpass $\mathrm{PtC}$ at this potential, clearly pointing out the influence of rapid mass transfer achieved by a hierarchical substrate.

The rotating ring disk electrode (RRDE) technique was applied to investigate the reaction pathway of GF $+\mathrm{N} 2+\mathrm{Fe} 1$ 1800. As shown in the plot of peroxide formation ratio (Figure 5a), a peak value of $4.57 \%$ is observed at $0.8 \mathrm{~V}$ vs RHE, which is due to the oxide substructure of the Pt surface 
and is characteristic of the outer-sphere reaction for $\mathrm{Pt}$ in an alkaline electrolyte. ${ }^{3} \mathrm{GF}+\mathrm{N} 2+\mathrm{Fe} 1$ 800, however, forms a greatly reduced amount of intermediate during the ORR (i.e., $0.31 \%$ at $0.8 \mathrm{~V}$ vs $\mathrm{RHE})$, indicating that the embedded $\gamma-\mathrm{Fe}_{2} \mathrm{O}_{3}$ nanoparticles can effectively enhance the $\mathrm{HO}_{2}{ }^{-}$binding and thus feature an improved selectivity of the $4 \mathrm{e}$ transfer pathway over the potential range of operation. The broad peak of peroxide formation of $\mathrm{GF}+\mathrm{N} 2 \_800$ and $\mathrm{GF}+\mathrm{N} 2+\mathrm{Fe} 1 \_800$, when the potential is lower than $\overline{0} .7 \mathrm{~V}$ vs RHE, can be assigned to the reduction of specifically absorbed oxygen on the substrate.

On the basis of the ETN values derived from RRDE measurements, the corresponding diffusion-corrected kinetic current density $\left(J_{\mathrm{K}}\right)$ was calculated and presented in the Tafel plots (Figure $5 b$ ). It is shown that $\mathrm{GF}+\mathrm{N} 2+\mathrm{Fe} 1 \_800$ possesses an onset potential (i.e., $J_{\mathrm{K}}$ reaches $0.5 \mathrm{~mA} \mathrm{~cm}{ }^{-2}$ ) similar to that of PtC but a much smaller Tafel slope (66.3 vs $83.5 \mathrm{mV} \mathrm{\textrm {dec } ^ { - 1 }}$ for $\mathrm{GF}+\mathrm{N} 2+\mathrm{Fe} 1 \_800$ and $\mathrm{PtC}$ ), which results in a 3 times higher $J_{\mathrm{K}}$ value in comparison to that for $\mathrm{PtC}$ at $0.8 \mathrm{~V}$ vs $\mathrm{RHE}$ ( 34.3 vs $10.96 \mathrm{~mA} \mathrm{~cm}^{-2}$ ). It is also noted in Figure $\mathrm{S} 6$ in the Supporting Information that the Tafel plots of GF $+\mathrm{N} 2+\mathrm{Fe} 1 \_800$ and $\mathrm{GF}+\mathrm{N} 2+\mathrm{Pt} 1 \_800$ (same synthesis route except using a Pt precursor) are almost parallel, with a potential shift of less than $10 \mathrm{mV}$. Such an observation confirms that the superior ORR kinetics of GF+N2+Fe_800 is achieved by the combined effect of both $\gamma$ - $\mathrm{Fe}_{2} \mathrm{O}_{3}$ with oxygen adsorption capability comparable to that of $\mathrm{Pt}$ and the hierarchically porous $\mathrm{GF}+\mathrm{N} 2800$ substrate with rapid mass transfer (the Tafel slope of $\overline{\mathrm{GF}}+\mathrm{N} 2 \_800$ is only $47.9 \mathrm{mV} \mathrm{dec}^{-1}$ ).

To further elucidate the ORR activity of GF+N2+Fe1_800, electrical impedance spectroscopy (EIS) was employed. The equivalent circuit of $\mathrm{RDE}$ (insert in Figure $5 \mathrm{c}$ ) consists of an uncompensated impedance $\left(I_{\mathrm{U}}\right)$ including (a) the resistance of the electrolyte $R_{\mathrm{E}}$ and (b) the interface of the RDE thin film $\left(R_{\mathrm{TF}}\right)$ partially reflecting the electrical conductivity of the catalysts and also reaction related components $\left(I_{R}\right)$ such as $(c)$ the kinetics-controlled process $R_{\mathrm{K}}$ and (d) the diffusion controlled process $R_{\mathrm{D}}$ of the catalytic oxygen reduction process. EIS is measured at the half-wave potential of each catalyst, since at this point, the current density increases the most quickly and the overall impedance reaches its smallest value under a $\mathrm{RDE}$ system. Since the uncompensated impedance $I_{U}$ is almost the same for each catalyst, and it is thus subtracted from the Nyquist plot (Figure 5c). It is clearly seen that both kinetics (the first semicircle) and diffusion (the second semicircle) affect the ORR process at this potential (the mixed kineticdiffusion region). As expected, $\mathrm{GF}+\mathrm{N} 2+\mathrm{Fe} 1800$ and GF $+\mathrm{N} 2 \_800$ possess similar overall impedance of $250 \Omega$, while $\mathrm{PtC}$ shows a much larger value of $360 \Omega$. It is also shown that $\mathrm{GF}+\mathrm{N} 2+\mathrm{Fe} 1 \_800$ shows an $R_{\mathrm{K}}$ value of ca. $120 \Omega$, slightly higher than that of GF+N2_800 (95 $\Omega$ ) but smaller than that for $\mathrm{PtC}(160 \Omega)$. The order of $R_{\mathrm{K}}$ is in good agreement with the trend in Tafel slope $\left(\mathrm{GF}+\mathrm{N} 2 \_800<\mathrm{GF}+\mathrm{N} 2+\mathrm{Fe} \_800<\right.$ $\mathrm{PtC})$, further confirming that the confinement of a suitable amount of NPMs on a highly hierarchical substrate can largely preserve its rapid mass transport.

The consistency of the superior ORR activity for GF $+\mathrm{N} 2+\mathrm{Fe} 1 \_800$ was verified by analyzing its corresponding electrode performance through the polarization curves $(V \approx i)$ in 0.1 and $6 \mathrm{M} \mathrm{KOH}$ (Figure 5d). It can be seen that the ORR catalytic activities follow the exactly the same trend, in spite of the fact that the internal impedance is significantly reduced after loading the catalysts on hydrophobic carbon paper and the resistance of the electrolyte decreases as the concentration of alkaline electrolyte increases ( 12 and $2.5 \Omega$ for 0.1 and $6 \mathrm{M}$ $\mathrm{KOH}$, respectively).

The stability of $\mathrm{GF}+\mathrm{N} 2+\mathrm{Fe} 1 \_800$ was evaluated using a chronoamperometry method. The current response is measured at $1600 \mathrm{rpm}$ and at the potential when the current density of GF+N2+Fe1_800 or PtC reaches $3 \mathrm{~mA} \mathrm{~cm}^{-2}$. After $20 \mathrm{~h}$, the relative current of $\mathrm{PtC}$ drops ca. $25.2 \%$ while a small loss of $3.8 \%$ is observed for $\mathrm{GF}+\mathrm{N} 2+\mathrm{Fe} 1 \_800$ (Figure 5e). In addition, the durability of $\mathrm{GF}+\mathrm{N} 2+\mathrm{Fe} 1 \_800$ was further assessed by cycling the catalysts between 0.2 and $1.2 \mathrm{~V}$ vs RHE for 5000 cycles. ${ }^{14 b, 20}$ The LSV of GF+N2+Fe1_800 after the test shows a negligible shift of $-3 \mathrm{mV}$ for its half-wave potential at $1600 \mathrm{rpm}$ (Figure S7 in the Supporting Information). The excellent stability and durability of GF $+\mathrm{N} 2+\mathrm{Fe} 1 \_800$ should be ascribed to the successful confinement of $\gamma-\mathrm{Fe}_{2} \mathrm{O}_{3}$ into the nitrogen-doped graphene framework and the strong interaction between those two. ${ }^{15}$

Finally, the activity of GF+N2+Fe1 800 is compared with those of other recently developed Fe-based ORR catalysts in alkaline electrolyte. The potentials of each catalyst at 0.5 and 3 $\mathrm{mA} \mathrm{cm}{ }^{-2}$ (measured at $1600 \mathrm{rpm}$ in RDE/RRDE) are plotted as the $X$ and $Y$ axes in Figure 5f, and thus the gap between those two potentials of each catalyst (i.e., the intercept of red angled lines) can largely reflect its Tafel slope. The influence of catalyst loading for RDE is also taken into account (see Table S3 in the Supporting Information for more details). It can be seen that, among more than 50 catalysts, only one of them ${ }^{6 b}$ shows a larger Tafel slope and two others ${ }^{4 b, 9 a}$ possess a potential at $3 \mathrm{~mA} \mathrm{~cm}^{-2}$ higher than those of GF+N2+Fe1_800. This result clearly demonstrates that the ORR performance of $\mathrm{GF}+\mathrm{N} 2+\mathrm{Fe} 1 \_800$ is among the best of existing Fe-based ORR catalysts, despite the fact that the type of Fe-based active site has not been fully optimized yet.

\section{CONCLUSIONS}

A two-step design approach has been suggested and implemented to achieve a highly efficient NPM-based ORR catalyst, nanoconfined maghemite in a hierarchical nitrogendoped graphene framework, which outperforms the commercial $\mathrm{PtC}$ in an alkaline electrolyte. The scheme ensures that the hierarchical porosity of the substrate is generated and optimized first, to enhance the pore volume for rapid mass transfer, and then an appropriate amount of active NPM catalyst is introduced to the optimized substrate to enhance oxygen adsorption and inhibit intermediate peroxide formation, with little compromise of the overall mass transfer capability.

Due to a combined effect of the highly porous substrate and the active $\gamma$ - $\mathrm{Fe}_{2} \mathrm{O}_{3}$ sites, $\mathrm{GF}+\mathrm{N} 2+\mathrm{Fe} 1 \_800$ displays performance superior to that of the commercial $\mathrm{PtC}$, including a higher half-wave reduction potential, better $4 \mathrm{e}$ pathway selectivity, smaller Tafel slope, faster kinetic current density, and longer lifetime. The superior activities of GF+N2+Fe1_800 (also comparable with the Pt counterpart, GF+N2+Pt1_800) suggest the wide applicability of the above design principle and the great potential of developing cost-effective and durable $\gamma$ $\mathrm{Fe}_{2} \mathrm{O}_{3}$-based catalysts.

\section{ASSOCIATED CONTENT}

\section{Supporting Information}

The Supporting Information is available free of charge on the ACS Publications website at DOI: 10.1021/acscatal.6b00531. 
Additional characterizations and electrochemical measurements (PDF)

\section{AUTHOR INFORMATION}

\section{Corresponding Authors}

*E-mail for K.Q.: k.qiu.12@ucl.ac.uk.

*E-mail for Z.G.: z.x.guo@ucl.ac.uk.

\section{Notes}

The authors declare no competing financial interest.

\section{ACKNOWLEDGMENTS}

This work was supported by the UK Engineering and Physical Sciences Research Council (EPSRC) under consortium grants (ref: EP/K002252/1, EP/K021192/1, and EP/L018330/1).

\section{REFERENCES}

(1) (a) Ge, X.; Sumboja, A.; Wuu, D.; An, T.; Li, B.; Goh, F. W. T.; Hor, T. S. A.; Zong, Y.; Liu, Z. ACS Catal. 2015, 5, 4643-4667. (b) Li, Q.; Cao, R.; Cho, J.; Wu, G. Adv. Energy Mater. 2014, 4, 1301415. (c) Tang, C.; Zhang, Q. J. Mater. Chem. A 2016, 4, 4998-5001.

(2) (a) Blizanac, B. B.; Ross, P. N.; Markovic, N. M. Electrochim. Acta 2007, 52, 2264-2271. (b) Wan, K.; Yu, Z.-P.; Li, X.-H.; Liu, M.-y.; Yang, G.; Piao, J.-H.; Liang, Z.-X. ACS Catal. 2015, 5, 4325-4332.

(3) (a) Ramaswamy, N.; Mukerjee, S. J. Phys. Chem. C 2011, 115, 18015-18026. (b) Ramaswamy, N.; Mukerjee, S. Adv. Phys. Chem. 2012, 2012, 491604.

(4) (a) Wang, Y.; Kong, A.; Chen, X.; Lin, Q.; Feng, P. ACS Catal. 2015, 5, 3887-3893. (b) Kong, A.; Zhu, X.; Han, Z.; Yu, Y.; Zhang, Y.; Dong, B.; Shan, Y. ACS Catal. 2014, 4, 1793-1800. (c) Lin, L.; Zhu, Q.; Xu, A.-W. J. Am. Chem. Soc. 2014, 136, 11027-11033. (d) Li, M.; Xiong, Y.; Liu, X.; Han, C.; Zhang, Y.; Bo, X.; Guo, L. J. Mater. Chem. A 2015, 3, 9658-9667.

(5) Garsuch, A.; Bonakdarpour, A.; Liu, G.; Yang, R.; Dahn, J. R. In Handbook of Fuel Cells; Wiley: Chichester, U.K., 2010; Vol. 5, Chapter 5 , pp $1-10$.

(6) (a) Jiang, Y.; Lu, Y.; Lv, X.; Han, D.; Zhang, Q.; Niu, L.; Chen, W. ACS Catal. 2013, 3, 1263-1271. (b) Cao, R; Thapa, R.; Kim, H.; Xu, X.; Gyu Kim, M.; Li, Q.; Park, N.; Liu, M.; Cho, J. Nat. Commun. 2013, 4, 2076. (c) Jahan, M.; Bao, Q.; Loh, K. P. J. Am. Chem. Soc. 2012, 134, 6707-6713. (d) Yao, Y.; Xiao, H.; Wang, P.; Su, P.; Shao, Z.; Yang, Q. J. Mater. Chem. A 2014, 2, 11768-11775. (e) Sanetuntikul, J.; Chuaicham, C.; Choi, Y.-W.; Shanmugam, S. J. Mater. Chem. A 2015, 3, 15473-15481. (f) Bo, X.; Li, M.; Han, C.; Zhang, Y.; Nsabimana, A.; Guo, L. J. Mater. Chem. A 2015, 3, 10581067. (g) Dong, Q.; Zhuang, X.; Li, Z.; Li, B.; Fang, B.; Yang, C.; Xie, H.; Zhang, F.; Feng, X. J. Mater. Chem. A 2015, 3, 7767-7772. (h) Zhou, R.; Qiao, S. Chem. Commun. 2015, 51, 7516-7519.

(7) (a) Yin, H.; Zhang, C.; Liu, F.; Hou, Y. Adv. Funct. Mater. 2014, 24, 2930-2937. (b) Zhang, S.; Zhang, H.; Liu, Q.; Chen, S. J. Mater. Chem. A 2013, 1, 3302-3308.

(8) (a) Xiao, M.; Zhu, J.; Feng, L.; Liu, C.; Xing, W. Adv. Mater. 2015, 27, 2521-2527. (b) Wu, Z.-Y.; Xu, X.-X.; Hu, B.-C.; Liang, H.W.; Lin, Y.; Chen, L.-F.; Yu, S.-H. Angew. Chem., Int. Ed. 2015, 54, 8179-8183. (c) Yang, W.; Liu, X.; Yue, X.; Jia, J.; Guo, S. J. Am. Chem. Soc. 2015, 137, 1436-1439. (d) Ranjbar Sahraie, N.; Paraknowitsch, J. P.; Göbel, C.; Thomas, A.; Strasser, P. J. Am. Chem. Soc. 2014, 136, 14486-14497. (e) Fan, X.; Peng, Z.; Ye, R.; Zhou, H.; Guo, X. ACS Nano 2015, 9, 7407-7418. (f) Domínguez, C.; Pérez-Alonso, F. J.; Salam, M. A.; Al-Thabaiti, S. A.; Peña, M. A.; García-García, F. J.; Barrio, L.; Rojas, S. Appl. Catal., B 2016, 183, 185-196. (g) Zhu, J.; Xiao, M.; Liu, C.; Ge, J.; St-Pierre, J.; Xing, W. J. Mater. Chem. A 2015, 3, 21451-21459. (h) Schnepp, Z.; Zhang, Y.; Hollamby, M. J.; Pauw, B. R.; Tanaka, M.; Matsushita, Y.; Sakka, Y. J. Mater. Chem. A 2013, 1, 13576-13581.

(9) (a) Liu, J.; Sun, X.; Song, P.; Zhang, Y.; Xing, W.; Xu, W. Adv. Mater. 2013, 25, 6879-6883. (b) Yang, G.; Choi, W.; Pu, X.; Yu, C. Energy Environ. Sci. 2015, 8, 1799-1807. (c) Wu, Z.; Yang, S.; Sun, Y.;
Parvez, K.; Feng, X.; Müllen, K. J. Am. Chem. Soc. 2012, 134, 90829085. (d) He, D.; Xiong, Y.; Yang, J.; Chen, X.; Deng, Z.; Pan, M.; Li, Y.; Mu, S. J. Mater. Chem. A 2015, DOI: 10.1039/C5TA09232A. (e) Sun, M.; Dong, Y.; Zhang, G.; Qu, J.; Li, J. J. Mater. Chem. A 2014, 2, 13635-13640. (f) Zhang, X.; Wang, X.; Le, L.; Ma, A.; Lin, S. J. Mater. Chem. A 2015, 3, 19273-19276.

(10) (a) Parvez, K.; Yang, S.; Hernandez, Y.; Winter, A.; Turchanin, A.; Feng, X.; Müllen, K. ACS Nano 2012, 6, 9541-9550. (b) Wen, Z.; Ci, S.; Hou, Y.; Chen, J. Angew. Chem., Int. Ed. 2014, 53, 6496-6500.

(11) (a) Qian, L.; Lu, Z.; Xu, T.; Wu, X.; Tian, Y.; Li, Y.; Huo, Z.; Sun, X.; Duan, X. Adv. Energy Mater. 2015, 5, 1500245. (b) Nam, G.; Park, J.; Choi, M.; Oh, P.; Park, S.; Kim, M. G.; Park, N.; Cho, J.; Lee, J.-S. ACS Nano 2015, 9, 6493-6501. (c) Lin, Q.; Bu, X.; Kong, A.; Mao, C.; Bu, F.; Feng, P. Adv. Mater. 2015, 27, 3431-3436. (d) Xie, Y.; Li, H.; Tang, C.; Li, S.; Li, J.; Lv, Y.; Wei, X.; Song, Y. J. Mater. Chem. A 2014, 2, 1631-1635.

(12) (a) Lee, J.-S.; Park, G. S.; Kim, S. T.; Liu, M.; Cho, J. Angew. Chem., Int. Ed. 2013, 52, 1026-1030. (b) Zhao, S.; Yin, H.; Du, L.; He, L.; Zhao, K.; Chang, L.; Yin, G.; Zhao, H.; Liu, S.; Tang, Z. ACS Nano 2014, 8, 12660-12668. (c) Li, Z.; Li, G.; Jiang, L.; Li, J.; Sun, G.; Xia, C.; Li, F. Angew. Chem., Int. Ed. 2015, 54, 1494-1498. (d) Hu, Y.; Jensen, J. O.; Zhang, W.; Cleemann, L. N.; Xing, W.; Bjerrum, N. J.; Li, Q. Angew. Chem., Int. Ed. 2014, 53, 3675-3679. (e) Hou, Y.; Huang, T.; Wen, Z.; Mao, S.; Cui, S.; Chen, J. Adv. Energy Mater. 2014, 4, 1400337. (f) Peng, H.; Liu, F.; Liu, X.; Liao, S.; You, C.; Tian, X.; Nan, H.; Luo, F.; Song, H.; Fu, Z.; Huang, P. ACS Catal. 2014, 4, 37973805. (g) Wei, J.; Liang, Y.; Hu, Y.; Kong, B.; Simon, G. P.; Zhang, J.; Jiang, S. P.; Wang, H. Angew. Chem., Int. Ed. 2016, 55, 1355-1359. (h) Song, P.; Wang, Y.; Pan, J.; Xu, W.; Zhuang, L. J. Power Sources 2015, 300, 279-284. (i) Dominguez, C.; Perez-Alonso, F. J.; Salam, M. A.; Al-Thabaiti, S. A.; Pena, M. A.; Barrio, L.; Rojas, S. J. Mater. Chem. A 2015, 3, 24487-24494. (j) He, C.; Zhang, J. J.; Shen, P. K. J. Mater. Chem. A 2014, 2, 3231-3236. (k) Yan, X.-H.; Xu, B.-Q. J. Mater. Chem. A 2014, 2, 8617-8622. (1) You, C.; Liao, S.; Qiao, X.; Zeng, X.; Liu, F.; Zheng, R.; Song, H.; Zeng, J.; Li, Y. J. Mater. Chem. A 2014, 2, 12240-12246. (m) Zhang, R.; He, S.; Lu, Y.; Chen, W. J. Mater. Chem. A 2015, 3, 3559-3567. (n) Liang, J.; Zhou, R. F.; Chen, X. M.; Tang, Y. H.; Qiao, S. Z. Adv. Mater. 2014, 26, 6074-6079.

(13) (a) Singh, K. P.; Bae, E. J.; Yu, J.-S. J. Am. Chem. Soc. 2015, 137, 3165-3168. (b) Niu, W.; Li, L.; Liu, X.; Wang, N.; Liu, J.; Zhou, W.; Tang, Z.; Chen, S. J. Am. Chem. Soc. 2015, 137, 5555-5562. (c) Strickland, K.; Miner, E.; Jia, Q.; Tylus, U.; Ramaswamy, N.; Liang, W.; Sougrati, M.-T.; Jaouen, F.; Mukerjee, S. Nat. Commun. 2015, 6, 7343. (d) Zhang, Y.; Fugane, K.; Mori, T.; Niu, L.; Ye, J. J. Mater. Chem. 2012, 22, 6575-6580. (e) Zhan, Y.; Lu, M.; Yang, S.; Xu, C.; Liu, Z.; Lee, J. Y. Chem CatChem 2016, 8, 372-379.

(14) (a) Bezerra, C. W. B.; Zhang, L.; Lee, K.; Liu, H.; Marques, A. L. B.; Marques, E. P.; Wang, H.; Zhang, J. Electrochim. Acta 2008, 53, 4937-4951. (b) Xia, B. Y.; Yan, Y.; Li, N.; Wu, H. B.; Lou, X. W.; Wang, X. Nat. Energy 2016, 1, 15006. (c) Chung, H. T.; Won, J. H.; Zelenay, P. Nat. Commun. 2013, 4, 1922. (d) Zitolo, A.; Goellner, V.; Armel, V.; Sougrati, M.-T.; Mineva, T.; Stievano, L.; Fonda, E.; Jaouen, F. Nat. Mater. 2015, 14, 937-942.

(15) (a) Wang, H.; Dai, H. Chem. Soc. Rev. 2013, 42, 3088-3113. (b) Liu, H.; Zheng, Y.; Wang, G.; Qiao, S. Z. Adv. Energy Mater. 2015, 5, 1401186. (c) Zhou, R.; Jaroniec, M.; Qiao, S.-Z. ChemCatChem 2015, 7, 3808-3817. (d) Gao, W.; Havas, D.; Gupta, S.; Pan, Q.; He, N.; Zhang, H.; Wang, H.-L.; Wu, G. Carbon 2016, 102, 346-356.

(16) Yaldagard, M.; Jahanshahi, M.; Seghatoleslami, N. World J. Nano Sci. Eng. 2013, 03, 121-153.

(17) Zadick, A.; Dubau, L.; Sergent, N.; Berthomé, G.; Chatenet, M. ACS Catal. 2015, 5, 4819-4824.

(18) Qiu, K.; Guo, Z. X. J. Mater. Chem. A 2014, 2, 3209-3215.

(19) (a) Alatalo, S.-M.; Qiu, K.; Preuss, K.; Marinovic, A.; Sevilla, M.; Sillanpää, M.; Guo, X.; Titirici, M.-M. Carbon 2016, 96, 622-630. (b) Chai, G.-L.; Hou, Z.; Shu, D.-J.; Ikeda, T.; Terakura, K. J. Am. Chem. Soc. 2014, 136, 13629-13640.

(20) Ferrero, G. A.; Preuss, K.; Fuertes, A. B.; Sevilla, M.; Titirici, M. M. J. Mater. Chem. A 2016, 4, 2581-2589. 
(21) (a) Liang, J.; Jiao, Y.; Jaroniec, M.; Qiao, S. Z. Angew. Chem., Int. Ed. 2012, 51, 11496-11500. (b) Lai, L.; Potts, J. R.; Zhan, D.; Wang, L.; Poh, C. K.; Tang, C.; Gong, H.; Shen, Z.; Lin, J.; Ruoff, R. S. Energy Environ. Sci. 2012, 5, 7936-7942. (c) Duan, J.; Chen, S.; Jaroniec, M.; Qiao, S.-Z. ACS Catal. 2015, 5, 5207-5234. (d) Qu, K.; Zheng, Y.; Dai, S.; Qiao, S. Z. Nano Energy 2016, 19, 373-381.

(22) Kim, W.; Suh, C.-Y.; Cho, S.-W.; Roh, K.-M.; Kwon, H.; Song, K.; Shon, I.-J. Talanta 2012, 94, 348-352.

(23) Biesinger, M. C.; Payne, B. P.; Grosvenor, A. P.; Lau, L. W. M.; Gerson, A. R.; Smart, R. S. C. Appl. Surf. Sci. 2011, 257, 2717-2730.

(24) Wang, D.-W.; Su, D. Energy Environ. Sci. 2014, 7, 576-591. 